\title{
A Message From the Editor-in-Chief
}

\author{
Ho-Joong Youn, MD, PhD
}

Editor-in-Chief, Korean Circulation Journal

Division of Cardiology, Department of Internal Medicine, College of Medicine, The Catholic University of Korea, Seoul, Korea

\section{Dear members of The Korean Society of Cardiology}

The KCJ has been published continually for 41 years, with its first issue being released on June 25, 1971. As a result of the increase in the frequency and size of publication, 2000 copies of the English version are issued twelve times a year and are sent to the members and libraries of domestic/foreign colleges. The publication homepage (www.e-kcj.org) and the online homepage (www.submission.e-kcj.org) of the KCJ would be proud websites for submissions and searches of manuscripts at an international level. It was recently amended as a journal that included author information, a cover page, and inner pages to meet international standards.

Now, the KCJ is the official journal of The Korean Society of Cardiology, The Korean Pediatric Heart Society, and The Korean Society of Lipidology and Atherosclerosis.

The KCJ is indexed/tracked/covered by PubMed, PubMed Central, Scopus, EMBASE, CAS, KoreaMed, Synapse, KoMCl, CrossRef, and Google Scholar, and is an international academic journal, both in name and reality.

Since 2010, 20\% of all manuscripts in the KCJ were submitted from foreign countries, and the total number of manuscripts has increased. The impact factor of the KCJ is about 0.5 as of 2012, and I am confident that it will grow to become a SCl-level international academic journal.

The KCJ needs the support and love of its members.

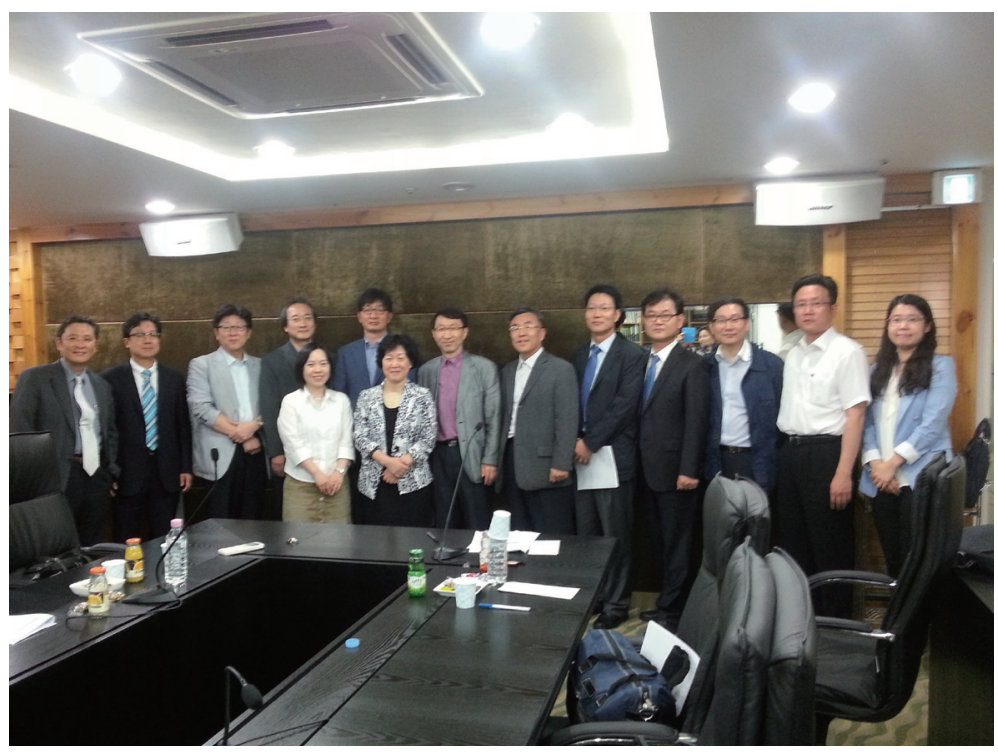

